\title{
Lujo hemorrhagic fever
}

INSERM

\section{Source}

INSERM. (1999). Orphanet: an online rare disease and orphan drug data base. Lujo hemorrhagic fever. ORPHA:319213

Lujo hemorrhagic fever, caused by the Lujo virus (a newly discovered Old World arenavirus) is a zoonotic disease from Zambia, Africa, whose reservoir is unknown and is characterized by fever and hemorrhagic manifestations with an extremely high fatality rate of $80 \%$ (in the 5 reported cases to date) and a moderate to high level of nosocomial transmission. 